\title{
PREDICTION OF THE ERROR GENERATED BY SMALIAN'S AND HUBER'S FORMULAE IN VOLUME MEASUREMENTS OF PinUs caribaea (MORELET).
}

\author{
S Hewage and SM C U P Subasinghe \\ Department of Forestry and Environmental Science, \\ University of Sri Jayewardenepura
}

One of the common methods of volume estimation is the use of mathematical equations. Among such equations, Huber's, Smalian's and Newton's formulae are commonly used and it is believed that Newton's formula which uses bottom, mid and top diameter of the $\log$ and $\log$ length gives most precise volume estimations than Smalian's or Huber's formulae. The latter two equations use only log length and end diameters and mid diameter respectively. Usually for volume calculations Huber's formula is used due to the involvement of less measurements (mid diameter and log length)

Present study was conducted in the 26 year old Pinus caribaea plantation in Yagirala Forest Reserve situated in the low country wet zone of Sri Lanka. In order to represent the whole area of the forest, stratified random sampling method was used and one $0.05 \mathrm{ha}$ sample plot was laid in each stratum. Altogether 3 plots were selected.

Each tree was divided into twelve one meter long sections using a ranging staff. Three diameters i.e., bottom, mid and top diameters of each section were measured using the Spiegel relascope. Other than section diameters, diameter at breast height (dbh) of the tree was measured using the diameter tape.

Cumulative section volumes per each tree were calculated separately from $1 \mathrm{~m}$ to $12 \mathrm{~m}$ using Huber's, Smalian's and Newton's formulae. other than the above method volume was calculated using section lengths separately up to twelve meter long sections using Newton's formula to test whether log length affect the Newton's volume. When tested there was no significant difference between two volume types. However, for further analysis Newton's volune calculated using the sectio.. length separately was used.

For each cumulative volume (i.e., $1 \mathrm{~m}$ to $12 \mathrm{~m}$ ) calculated using different formulae were statistically tested using one way ANOVA. According to the results $6 \mathrm{~m}$ is the maximum length for Huber's formula to predict the volume accurately. However it does not show a significant difference between Smalian's and Newton's formulae up to twelve meter section length.

Generally Huber's formula underestimates and Smalian's formula overestimates the volume. Therefore it is recommended to use Huber's formula for volume calculations due to it's ease of use, keeping the log length shorter than $6 \mathrm{~m}$.

Proceedings of the Ninth Annual Forestry and Environment Symposium 2003 of the Department of Forestry and Environmental Science, University of Sri Jayewardenepura, Sri Lanka 